NBER WORKING PAPER SERIES

\title{
WHY IS THE TEEN BIRTH RATE IN THE UNITED STATES SO HIGH AND WHY DOES IT MATTER?
}

\author{
Melissa Schettini Kearney \\ Phillip B. Levine
}

Working Paper 17965

http://www.nber.org/papers/w17965

\author{
NATIONAL BUREAU OF ECONOMIC RESEARCH \\ 1050 Massachusetts Avenue \\ Cambridge, MA 02138 \\ March 2012
}

The authors thank the editors of the Journal of Economic Perspectives (David Autor, Charles Jones, John List, Ann Norman, and Timothy Taylor) for helping to shape this article. Any views expressed are those of the authors alone. The views expressed herein are those of the authors and do not necessarily reflect the views of the National Bureau of Economic Research.

NBER working papers are circulated for discussion and comment purposes. They have not been peerreviewed or been subject to the review by the NBER Board of Directors that accompanies official NBER publications.

(C) 2012 by Melissa Schettini Kearney and Phillip B. Levine. All rights reserved. Short sections of text, not to exceed two paragraphs, may be quoted without explicit permission provided that full credit, including (c) notice, is given to the source. 
Why is the Teen Birth Rate in the United States so High and Why Does it Matter?

Melissa Schettini Kearney and Phillip B. Levine

NBER Working Paper No. 17965

March 2012

JEL No. I28,J13

\begin{abstract}
$\underline{\text { ABSTRACT }}$
This paper examines two aspects of teen childbearing in the United States. First, it reviews and synthesizes the evidence on the reasons why teen birth rates are so uniquely high in the United States and especially in some states. Second, it considers why and how it matters. We argue that economists' typical explanations are unable to account for any sizable share of the geographic variation. We describe some recent analysis indicating that the combination of being poor and living in a more unequal (and less mobile) location, like the United States, leads young women to choose early, non-marital childbearing at elevated rates, potentially because of their lower expectations of future economic success. Consistent with this view, the most rigorous studies on the topic find that teen childbearing has very little, if any, direct negative economic consequence. If it is explained by the low economic trajectory that some young women face, then it makes sense that having a child as a teen would not be an additional cause of poor economic outcomes. These findings lead us to conclude that the high rate of teen childbearing in the United States matters mostly because it is a marker of larger, underlying social problems.
\end{abstract}

\author{
Melissa Schettini Kearney \\ Department of Economics \\ University of Maryland \\ 3105 Tydings Hall \\ College Park, MD 20742 \\ and NBER \\ kearney@econ.umd.edu \\ Phillip B. Levine \\ Department of Economics \\ Wellesley College \\ 106 Central Street \\ Wellesley, MA 02481 \\ and NBER \\ plevine@wellesley.edu
}




\section{INTRODUCTION}

Teens in the United States are far more likely to give birth than in any other industrialized country in the world. U.S. teens are two and a half times as likely to give birth as compared to teens in Canada, around four times as likely as teens in Germany or Norway, and almost 10 times as likely as teens in Switzerland. Among more developed countries, Russia has the next highest teen birth rate after the United States, but an American teenage girl is still around 25 percent more likely to give birth than her counterpart in Russia. Moreover, these statistics incorporate the almost 40 percent fall in the teen birth rate that the U.S. has experienced over the past two decades. Differences across U.S. states are quite dramatic as well. A teenage girl in Mississippi is four times more likely to give birth than a teenage girl in New Hampshire — and 15 times more likely to give birth as a teen compared to a teenage girl in Switzerland.

This paper has two overarching goals: understanding why the teen birth rate is so high in the United States and understanding why it matters. Thus, we begin by examining multiple sources of data to put current rates of teen childbearing into the perspective of cross-country comparisons and recent historical context. We examine teen birth rates alongside pregnancy, abortion, and "shotgun" marriage rates as well as the antecedent behaviors of sexual activity and contraceptive use. We seek insights as to why the rate of teen childbearing is so unusually high in the United States as a whole, and in some U.S. states, in particular. We argue that explanations that economists have tended to study are unable to account for any sizable share of the variation in teen childbearing rates across place. We describe some recent empirical work demonstrating that variation in income inequality across U.S. states and developed countries can explain a sizable share of the geographic variation in teen childbearing. To the extent that income inequality is associated with a lack of economic opportunity and heightened social 
marginalization for those at the bottom of the distribution, this empirical finding is potentially consistent with the ideas that other social scientists have been promoting for decades, but which have been largely untested with large data sets and standard econometric methods.

Our reading of the totality of evidence leads us to conclude that being on a low economic trajectory in life leads many teenage girls to have children while they are young and unmarried and that poor outcomes seen later in life (relative to teens who do not have children) are simply the continuation of the original low economic trajectory. That is, teen childbearing is explained by the low economic trajectory but is not an additional cause of later difficulties in life. Surprisingly, teen birth itself does not appear to have much direct economic consequence.

Moreover, no silver bullet such as expanding access to contraception or abstinence education will solve this particular social problem. Our view is that teen childbearing is so high in the United States because of underlying social and economic problems. It reflects a decision among a set of girls to "drop-out" of the economic mainstream; they choose nonmarital motherhood at a young age instead of investing in their own economic progress because they feel they have little chance of advancement. This thesis suggests that to address teen childbearing in America will require addressing some difficult social problems: in particular, the perceived and actual lack of economic opportunity among those at the bottom of the economic ladder.

\section{Documenting Patterns}

We begin by describing the sources of data that researchers use to examine teen fertility, along with the sexual activity and contraceptive use that lead to different fertility outcomes. We detail the patterns in these behaviors over time and across locations. Finally, we examine 
differences in teen fertility and its antecedent behavior by demographic group, including race and ethnicity.

\section{A. Data Sources}

Researchers focusing on teen fertility in the United States have at least five main sources of data at their disposal. Perhaps the most important are the natality data from the Vital Statistics system, which contain all of the information from birth certificates. The main strength of these data is their universal nature and large sample size; data exist for virtually every live U.S. birth. However, these data are limited to the information on a birth certificate; that is, we know the mother's age and education, race/ethnicity, marital status, birth weight, and a limited number of additional pieces of information, but little else.

The National Surveys of Family Growth (NSFG) provide a wealth of data on the sexual activity, contraceptive use, and pregnancy histories of a national sample of 7,000 to 10,000 women of childbearing age (15 to 44). These surveys were completed in 1982, 1988, 1995, and 2002 (earlier surveys in 1973 and 1976 only included married women, limiting their value for present purposes). Beginning in 2006, the survey design changed from one larger survey every several years to a smaller annual survey; data from 2006-2008 are currently available. The survey oversamples minorities and teens, but is otherwise nationally representative. For an analysis of teen fertility, the sample size of teens in the survey contemporaneously is not that large. On the other hand, pregnancy histories can be used to generate teen fertility outcomes for virtually all women in the sample (excluding those who are, say, only 15 years old on the survey date).

Data from the Youth Risky Behavior Surveillance (YRBS) system provides useful information on the activities of school-age teens. These data are collected biannually for students 
who respond to the survey at school. Students are asked about their sexual activity and contraceptive use. Respondents are typically between 14 and 18, which is not quite the same age range as a traditional measure of teen fertility — typically ages 15 to 19 - but is close enough to draw useful inferences. The sample sizes are reasonably large - in the thousands per year. One disadvantage is that not all states participate in the program in every survey year. Another disadvantage is that the sample does not include high school dropouts, which is a group that may have a higher risk of teen pregnancy.

Two additional sources of data are at our disposal. ${ }^{1}$ The Guttmacher Institute collects and reports aggregate data on abortions and also aggregate numbers for pregnancy, and fertility. The Family and Fertility Survey (FFS) is a dataset that is much like the National Surveys of Family Growth, but it includes a survey like this from several more developed countries. In most countries, the data are available for the early to mid 1990s (the 1995 National Survey of Family Growth is the American contribution to the FFS). In this paper, we use these five datasets.

\section{B. Geographic and Time-series Variation in Teen Fertility Rates}

Figure 1 and Table 1 display the substantial geographic variation in the teen birth rate across countries and across U.S. states, respectively, in 2009. Typical developed countries have a teen birth rate in the range of 5 to 15 births per 1,000 women between the ages of 15 and 44 . The U.S. teen pregnancy rate is 37.9 in 2009 (although it fell to 34.3 in 2010). Some New England states with teen birth rates under 20 are fairly close to other developed countries and are comparable to that in other English-speaking countries like Australia, Ireland, and the United Kingdom. Some southern states with teen birth rates over 60 are extreme outliers.

\footnotetext{
${ }^{1}$ The National Longitudinal Survey of Adolescent Health (often called "adhealth") includes similar data, but we have not found this to be a useful source of data for our purposes. The focus of these data is the interrelationships between respondents. This data source is less frequently used for more traditional cross-sectional evidence.
} 
Figure 2 shows the teen birthrate since 1976, using Vital Statistics data. ${ }^{2}$ The teen birth rate holds roughly constant through the late 1970s and most of the 1980s between 50 and 55 births per 1,000 women between the ages of 15 and 19. A large blip developed in the time series beginning in the late $1980 \mathrm{~s}$, and the teen birth rate rose to a level of around 60 births per 1,000 teenage women in the early 1990s. It has been generally declining since then. The teen birth rate was 37.9 per thousand in 2009, down from the peak of 61.8 in 1991. Figure 2 also shows that the composition of teen births has shifted dramatically towards unmarried women. The birth rate among unmarried teens used to be considerably lower than that for all teens, but in 2009, 87 percent of teen births were to unmarried mothers (Martin et al. 2011).

Trends in teen births can be driven by changes in the likelihood of a pregnancy or changes in the likelihood of aborting a pregnancy once it occurs (we assume miscarriage rates are roughly stable over time). Figure 2 also displays trends in the pregnancy and abortion rate, again as measured per 1,000 women age 15 to 19 . Pregnancies and abortions were roughly flat during the period in which teen births were flat through the late 1980s. During this period, roughly 10 percent of teens got pregnant and 4 percent had an abortion each year. The spike in teen births in the early 1990s was driven almost entirely by an increase in the pregnancy rate; almost 12 percent of teens got pregnant at the peak in 1990. Clearly, the recent decline in teen births is not attributable to greater use of abortion; instead, it is the result of fewer teens getting pregnant. More recently, 7 percent of teens got pregnant and 2 percent had an abortion each year.

Fertility outcomes for teens differ dramatically by race and ethnicity. Figure 3 displays teen birth rates for Hispanics, non-Hispanic blacks, and non-Hispanic whites beginning in 1989 (the first year in which race/ethnicity were separately identified). Teen birth rates for white, non-

\footnotetext{
${ }^{2}$ Although the data go back further than that, we focus on the period after the 1960 s and early 1970 s, which saw dramatic legal changes in access to abortion and contraception and the sexual revolution..
} 
Hispanic women have been considerably lower than the other groups over the entire period, falling in the range of 25 to 40 or so births per 1,000 women as opposed to rates that are two to three times that for the other groups. Although all groups have experienced a substantial decline in teen birth rates since the early 1990s, the decline for black, non-Hispanic teens has been particularly notable. For this group, the teen birth rate fell by half from 118.2 to 59 between 1991 and 2009. Presently, Hispanic teens have the highest teen birth rate at a level of 70.1 per thousand, which is nonetheless a sizable decline from a rate of 104.6 per thousand in 1991. For all race/ethnic groups, the declines in teen births are driven entirely by declines in pregnancies, not increases in abortion (Guttmacher Institute, 2010).

\section{Trends in Fertility Outcomes by Age 20}

All of the statistics reported in the preceding section are based on the behavior of teens in a given year. A related, but not identical, issue is the behavior of women over all of their teen years. For purposes of illustration, consider 100 teenage girls between the ages of 15 and 19 , with 20 girls at each particular age and 5 percent give birth in a given year. It could be that only 5 percent of teens ever give birth as a teenager - say one teen at each age $(15,16,17,18$, and 19) - if the same mothers give birth year after year. Alternatively, if the only teens who give birth do so at age 19 , then if 5 percent of teens give birth per year, it would imply that 25 percent of the 19 year-olds give birth, and 25 percent of women would end up giving birth by the time they reach age 20. In this section, and in subsequent analyses, we use individual-level data from the National Surveys of Family Growth to construct cumulative statistics by birth cohort.

Roughly 20 percent of women who have turned age 20 over the past 30 or so years have given birth as a teen. This statistic has fluctuated similarly to what we see with point-in-time statistics in Figure 2, with a spike for the cohorts hitting age 20 in the early 1990s and declining 
in recent years. The comparison of a 5 percent annual teen birth rate to a typical rate of teen childbearing for a birth cohort of around 20 percent suggests that roughly 20 percent of teen births are not first births. For the most recent cohorts, the likelihood of giving birth as a teen has fallen to 17 percent. Again, mothers who have never married have become more prominent among those giving births as teens.

We can also divide these data by the level of education obtained by the mother of the teenager. Although the exact composition of teens across maternal education categories varies by birth cohort, as an approximation 30 percent of teen mothers have mothers who dropped out of high school, 40 percent have mothers who are high school graduates, and 30 percent have mothers who attended college. Daughters of women who have dropped out of high school have children as teens at a rate in the vicinity of 33 percent. Daughters of women who have attended some college do so at around one-third this rate. However, the middle group - that is, daughters of women who are high school graduates but have not attended any college-is the group driving the rise and fall in the overall teen birth rate. This middle group saw by far the sharpest rise in the probability of giving birth by age 20 from 19 percent in 1990 to 29 percent in 1998, before falling back to 16 percent by 2006 .

The National Surveys of Family Growth data also allows us to investigate how each pregnancy was resolved. We focus on those teen pregnancies that began when the women were unmarried and track whether they led to a nonmarital birth, a marital birth, a miscarriage, or an abortion. The dramatic change here is that so-called "shotgun marriages" (meaning those that take place after the pregnancy but before the birth) have fallen throughout the period as nonmarital births have risen. ${ }^{3}$ In the 1970 s, nearly 40 percent of all nonmarital pregnancies

\footnotetext{
${ }^{3}$ Akerlof, Yellen, and Katz (1996) show that these trends for all women (not just teens) have been falling since the 1960s.
} 
resulted in a shotgun marriage. Now that rate has fallen under 10 percent. Conversely, nearly 40 percent of nonmarital pregnancies resulted in a nonmarital birth in 1976, but since the mid 1990s that has been in the range of $65-70$ percent of all teen pregnancies. With fewer abortions and fewer shotgun marriages among pregnant, unmarried women over the past few decades, a substantial majority of unmarried pregnant teens now give birth outside of marriage.

The final category here is pregnancies not carried to term, which can include either an abortion or a miscarriage. Abortions are notoriously underreported in survey data, so by including all pregnancies that are not resolved by birth, we do not have to worry about separately identifying abortions and miscarriages. Under the assumption that the rate of miscarriages has been roughly constant over time, we can interpret trends in so-called uncompleted pregnancies as being driven by changes in the use of abortion. We see an increase in the rate of uncompleted pregnancies from 20-25 percent in 1976 and 1977 to about 30-35 percent in the mid 1980s, followed by a decline back to about $20-25$ percent by the mid 1990s and relative stability in this outcome since then.

\section{Geographic Comparisons of Pregnancies and Abortions}

How does the variation in teen birth rates across countries and U.S. states reflect differences in pregnancy rates and abortion rates? $?^{4}$ We present some summary data in Table 2. For our international comparison, we highlight numbers from the United States, United Kingdom, Germany, and Denmark. This set is chosen because abortion data is available for all four of these countries, and because the countries span most of the range of country teen birth

\footnotetext{
${ }^{4}$ Pregnancy rates are reported by the Guttmacher Institute (2010) for the United States and for separate states. For the other countries, we take the ratio of the estimated number of pregnancies to the sum of abortions and births in the United States as an adjustment factor to account for miscarriage and apply that ratio to the sum of abortions and births in the other countries. This approach assumes a constant miscarriage rate across countries.
} 
rates reported in Figure 1. We also report numbers from Mississippi and New Hampshire, the U.S. states with the highest and lowest teen birth rates.

The main finding that emerges from these data is that pregnancy rates across locations line up very closely with birth rates. Differences in pregnancy rates appear to be the primary driver of differences in birth rates. Nonetheless, there are some interesting patterns in abortion rates. For instance, the lower rate of abortion in Germany relative to Denmark means that in Germany more births result from fewer pregnancies. The United States also has a relatively low rate of abortion conditional on pregnancy, as compared to the other three countries. This pattern holds despite the fact that abortion laws are relatively more lenient in the United States, certainly relative to Germany and the United Kingdom (Levine, 2004). We also see that the lowest teen birth rate U.S. states, like New Hampshire, have teen pregnancy and abortion rates that are comparable to many other developed countries. In Mississippi, in contrast, 8 percent of female teens become pregnant each year, and few have abortions.

\section{III.THE Roles OF SeXUal ACTIVITY AND CONTRACEPTIVE USE}

The earlier discussion (for example, in Figure 2 and Table 2) shows that the dramatic decline in teen births in the United States and the variation across countries is largely (although perhaps not exclusively) attributable to patterns in teen pregnancy, not use of abortion. This section explores to what extent the geographic variation in the likelihood of teen pregnancy is generated by a variation in teen sexual activity versus rates of contraceptive use among those who are sexually active. ${ }^{5}$

\footnotetext{
${ }^{5}$ In a companion paper (Kearney and Levine 2012), we focus on the relative contributions of changes in sexual activity versus contraceptive use in understanding the downward trend in teen birth rates in the United States.
} 


\section{A. Descriptive statistics}

Figure 4 displays a scatter plot across U.S. states of the percentage of teens that are sexually active - that is, who have engaged in sexual intercourse in the past three months - and the percentage of sexually active teens who used a form of contraception the last time they had sex. To calculate these statistics, we used data from the 2007 and 2009 Youth Risky Behavior Surveillance surveys, which contain information on these outcomes for 41 states. On average, 36 percent of teens are sexually active, but that statistic ranges from 28 percent in Colorado and Vermont to over 45 percent in Georgia and Mississippi. Contraceptive use is very high in these data; an average of 86 percent of teens that had sex in the last three months used some form of contraception at last intercourse. Again, a tremendous amount of variation across states exists, ranging from a high of over 90 percent in states like Maine, New Hampshire, and Vermontwhich are among the lowest teen birth rate states - to 81 percent in states like Texas and New Mexico, which are among the highest teen birth rates states. Interestingly, the two statistics across states are negatively correlated, although only weakly $(r=-0.21)$. These comparisons suggest the importance of both sexual activity and contraceptive use in driving variation in teen birth rates; we conduct a more formal decomposition of the relative importance of the two components subsequently.

International comparisons suggest that contraceptive use among U.S. teens is lower than in other developed countries (although the data available for such an exercise is somewhat limited), and this more than offsets the lower rate of sexual activity among U.S. teens, leading ultimately to a higher birth rate for U.S. teens. The most recent data for all teens, reported in Darroch et al. (2001), is now 15 to 20 years old. At that time, teens in the United States were somewhat less likely to be sexually active than teens in other countries. In the United States, 58.7 
percent of teens had intercourse in the past three months, whereas 62.2 percent, 63.9 percent, and 78.7 percent had sex in Great Britain, France, and Sweden, respectively. Contraceptive use was lower among U.S. teens, however, with 20 percent of teens failing to use any form of contraception at last intercourse, compared to 4 to 12 percent in these same three countries. More recent data from the early 2000s reported in Godeau, Gabhainn, Vignes, Ross, Boyce, and Todd (2008) and Santelli, Sandfort, and Orr (2008) focus explicitly on the behavior of 15 yearolds using data from the Youth Risky Behavior Surveillance in the United States and the Health Behaviour in School-Aged Children study in other countries. These data show that 18, 29, and 40 percent of 15 year-olds have ever had sex in France, Sweden, and England whereas our own calculation suggests that the rate in the United States is 23 percent, again suggesting that U.S. teens are toward the lower end of this distribution. In terms of contraception, Godeau, Gabhainn, Vignes, Ross, Boyce, and Todd (2008) report that 74, 83, and 90 percent of 15 year-olds in Sweden, England, and France used either the condom or pill at last sexual intercourse, as compared to only 66 percent of 15 year-old girls in the U.S. Of course, the focus on 15 year-olds in this comparison is somewhat limiting.

Within the United States, teen sexual activity is trending downward and contraceptive use is trending upward. Based on our analysis of National Surveys of Family Growth and Youth Risky Behavior Surveillance data over roughly the past two decades, we find that the percentage of teens that are sexually active has fallen from around 40 to 33 percent since around 1990 (although the precise levels and specific years are somewhat different across datasets). The prevalence of contraceptive use at last intercourse has risen in each survey from around 80 percent to 85 percent. Patterns of sexual activity and contraceptive use across racial and ethnic 
groups are generally consistent with differences in levels and trends in fertility outcomes across these groups.

\section{B. Decomposition of fertility rates into sexual activity and contraceptive use}

In this section, we undertake a decomposition exercise to determine the extent to which differences in the teen birth rate across regions can be attributed to teen sexual activity or contraceptive use. ${ }^{6}$ We emphasize that such an exercise only serves to understand the mechanistic drivers of teen birth rates. A more substantive analysis regarding the underlying reason why teens behave differently across time and place requires more sophisticated methods that can enable us to draw causal conclusions about behavioral responses.

We take advantage of Youth Risky Behavior Surveillance (YRBS) data between 1991 and 2007 and the observed teen birth rates in the subsequent years (1992-2008) by state to relate sexual activity and contraceptive use to teen fertility. ${ }^{7}$ Data from the YRBS reflect the behavior of high school-age (14 to 18 years-old) females. If they become pregnant, the birth would occur nine months later, at which point the vast majority would fit into the 15-to-19 year-old category that is captured by traditional measures of teen fertility. So we link the YRBS survey year with the teen birth rate in the following year. (We are not able to use the 2009 YRBS, which is currently available but cannot be linked to 2010 teen birth rates, as these are not yet available by

\footnotetext{
${ }^{6}$ Santelli, Lindberg, Finer, and Singh (2007) focus on the relative contributions of the two types of behavioral changes to describe the trend towards lower teen fertility. They start with the rates of sexual activity in the past three months and the likelihood of using contraception at last intercourse, but they focus specifically on the method of contraception used. Then they make a series of assumptions based on the percentage of teens who would get pregnant if they used no contraception (which is a function of sexual activity and the likelihood of pregnancy in its absence) and the effect of various forms of contraception on reducing that percentage. Then they apply observed changes in rates of sexual activity and contraceptive use to predict how much each one would have reduced the pregnancy rate. Comparing these predictions with actual declines enables them to decompose the overall decline into the two components. The results of their analysis suggest that about three-quarters of the decline in teen birth rates between 1995 and 2002 are attributable to greater use of contraception. We take a totally different approach to this question that is far less reliant on assumptions.

${ }^{7}$ Using analogous methods, in Kearney and Levine (2012), we find that reduced sexual activity and increased contraceptive use can explain 35 percent and 65 percent, respectively, of the decline in teen childbearing.
} 
state.) We then estimate regression models of the state-year teen birth rate as a function of measures of sexual activity and contraceptive use by state-year to determine how changes in these behaviors are linked to changes in teen birth rates. ${ }^{8}$

The results of regressions based on this analysis are presented in Table 3. The dependent variable in each model is the probability of giving birth as a teen in a year. The independent variables are share of teenagers in a state in a given year who have engaged in sexual activity in the previous three months along with measures of alternative contraceptive choices. The left panel focuses on the broader measure of whether any contraception was used at last intercourse, while the right panel of the table breaks up methods of contraception into specific forms. Estimates from these models indicate the effectiveness of alternative forms of contraception in reducing pregnancy as used in practice for this sample of teenagers and do not necessarily correspond to their reported efficacy when used as prescribed.

From the left panel of Table 3, the estimated coefficient on using contraception if sexually active is actually larger in absolute value than the estimated coefficient on being sexually active. This result, taken literally, does not make sense-since abstinence has to be the strongest form of contraception. This puzzle could be explained, for instance, by a lower rate of sexual activity among those who use contraception. However, the two estimated coefficients are not statistically distinguishable. These results indicate that a woman who reports engaging in sexual activity in the preceding three months has about a 16 percent chance of getting pregnant and giving birth. Using contraception can dramatically reduce the probability of getting pregnant, perhaps to the point of eliminating it entirely. The results in the right panel indicate that the pill

\footnotetext{
${ }^{8} \mathrm{We}$ use the size of the teen population in each state/year cell as weights in these regressions. State-level data in the Youth Risky Behavior Surveillance (YRBS) data are not available in every state in every year, and some states do not ask sexual activity questions in some (or all) years. In total, our dataset for this exercise is comprised of 167 state/year pairs. We used YRBS microdata to construct the state/year aggregates; these data are not publicly available, but can be obtained from the Centers for Disease Control.
} 
is the most effective form of birth control. Condoms are found to be about three-quarters $(.120 / .156)$ as effective as the pill. Although we do not find that Depo Provera is particularly effective, this is probably attributable to the very low rates of its use in these data, suggesting that the measurement of its use may be error ridden. Use of the withdrawal method is not found to be related to a reduction in teen fertility (although this could be attributable to other factorsperhaps those using withdrawal are having sex more often).

We apply the results in the left panel of the table to determine the relative contribution of reduced sexual activity and increased contraceptive use in explaining differences in teen birth rates across states and countries. Based on our earlier discussion, as a rough approximation, American teens are 10 percentage points less likely to be sexually active and 15 percentage points less likely to use contraception if they are sexually active. Our regression results indicate that the lower rate of sexual activity would reduce the teen birth rate by about 1.6 percentage points $(10 \times 0.162)$ and the lower rate of contraceptive use would increase the teen birth rate by 2.8 percentage points $(15 \mathrm{x}-0.186)$. On net, teen births would be 1.2 percentage points higher in the United States, which translates to a teen birth rate that is 12 points higher per 1,000 than in other countries. Based on the statistics reported in Figure 1, the observed difference is considerably greater than that.

Across states, the data suggest that it would not be out of the question for some states to have a 10 percentage point higher rate of teen sexual activity and a 10 percentage point lower rate of contraceptive use compared to other states. Applying the above approach, our estimates would generate corresponding teen birth rates that are 16 points higher per 1000 for the higher sexual activity and 18 points higher for the lower rates of contraceptive use, totaling 34 points per 1000. This is close to the roughly 40 point per 1000 gap that exists between high and low 
teen birth rate states. It suggests that these differences are roughly equally attributable to differences in sexual activity and contraceptive use.

For some analysts, these results would lead immediately to a call for more abstinence education and/or increased accessibility of contraception. ${ }^{9}$ However, jumping from a mechanistic decomposition to a policy recommendation ignores the underlying causes of any changes in behavior. Why did contraceptive use rise in the United States? Why are sexually active teens in Europe more likely to use contraception? It is not obvious that teens in the U.S. have more information or better access now than they used to. Nor is it obvious that information or access is better for teens in Europe. If we randomly assigned some U.S. teens to have greater access to contraception, would it affect the rate of childbearing among these teens? Perhaps not. To understand more fully what is driving the patterns in teen fertility that we observe, we need to go further and understand why teens in some places or in some years are more or less likely to use contraception or to abstain from sex.

\section{IV.Standard Models, Prescriptions, ANd Evidence}

The standard economic model of childbearing considers an individual who maximizes utility over children and other consumption subject to a budget constraint (for example, Becker and Lewis, 1973). Preferences are generally assumed to be fixed, and explanations have focused on differences in constraints, like policies making welfare more or less attractive, policies making abortion more or less readily available, and policies increasing access to low-cost

\footnotetext{
${ }^{9}$ Boonstra (2002, p. 8) provides an example: "If recent declines in teen childbearing are the result of fewer teens getting pregnant in the first place, the obvious next question is: why? Are fewer teens avoiding pregnancy by abstaining from sex, or are those who are having sex using contraception more successfully? Not surprisingly, the answer is: both. But deconstructing that answer is critical, because it goes to the heart of a number of relevant and timely public policy questions, among them the debate over public funding for abstinence-only education and for more-comprehensive approaches." Santelli, Linberg, Finer, and Singh (2007) express similar views.
} 
contraception. Moffitt $(1998,2003)$ reviews the evidence on the link between welfare benefits and nonmarital childbearing, including teen childbearing. The general consensus is that more generous welfare benefits have a modest positive effect on rates of nonmarital childbearing. However, the lower rate of teen childbearing in Europe with its much more generous welfare system provides a counterexample and prima facie case against the hypothesis that social support is largely to blame for high rates of teen childbearing in the United States. It also appears that the redesign of welfare reform in 1996 had only minor effects on rates of teen childbearing, at best (for example, Kearney, 2004; Grogger and Karoly, 2005).

Levine (2004) reviews the evidence on the link between abortion policy and fertility outcomes and finds that restrictive abortion policies such as parental notification laws or mandatory delay periods are not associated with higher rates of teen childbearing. In Kearney and Levine (2009), we examine expanded access to Medicaid family planning services during the 1990 s and early 2000s. We find that it led to statistically significant reductions in teen childbearing, on the order of a 4 percent reduction. But this effect is not sufficiently large such that one could conclude that limited access to free contraception is a primary driver of teen childbearing rates or that expanding access further would drive the rates down to European levels, for example.

In Kearney and Levine (2012), we econometrically investigate the effects of an extensive list of state-level policies on state-level teen birth rates using Vital Statistics birth data between 1981 and 2008. The list of policies we examine include: welfare benefit levels and welfare reform, expansions of Medicaid family planning services to non-Medicaid recipients; legal abortion restrictions; implementation of the State Children's Health Insurance Program (S-CHIP) (which provides health insurance to children and teens who do not otherwise qualify for Medicaid under traditional guidelines); a measure of federal abstinence education funding; and 
indicator variables for whether the state mandates sex education or contraception counseling. We also consider the role of state-level economic factors, including the unemployment rate. We include a rich set of demographic controls, including the racial/ethnic composition of the state female teenage population, and broader population characteristics, including the percent married, the percent aged 15-19, and the educational composition of the state population. We control for mean differences across states, shared year effects, and state-specific time trends. We estimate regressions for all births, and then separately for demographic subgroups defined by age, race/ethnicity, and marital status. We also examine abortion and pregnancy outcomes, though those analyses are limited by data and generally do not yield statistically precise estimates.

The results of this analysis are consistent with past research. We find that the Medicaid Section 1115 family planning waivers, which expanded eligibility for publicly funded family planning services, reduce teen fertility. Lower levels of welfare benefits also lead to lower rates of teen childbearing. Neither of these effects are sufficiently large to explain any sizable share of the geographic variation we observe in the data or the dramatic drop in teen birth rates over the past 20 years. Other policy interventions, including abortion policies, sex education, abstinence education, and SCHIP implementation are not found to have a statistically significant, causal impact on teen fertility.

In short, the standard policy prescriptions that are often advocated to alter rates of teen childbearing do not come close to explaining the extensive geographic variation that exists. To be sure, this evidence supports expanding access to free or subsidized contraception for teenagers, but it will not come close to a full solution for teen childbearing. Given that these policies cannot explain much cross-state variation, we are skeptical that a comparable analysis 
using similar policy variation across countries (as difficult as it would be to construct these measures) would explain cross-country differences.

\section{The ECONOMics OF MARginalization AND HopelessnesS}

Social scientists outside economics have been studying and debating the causes and consequences of early nonmarital childbearing for nearly half a century. An early report made famous by its lead author, Daniel Patrick Moynihan (U.S. Department of Labor, 1965) drew attention to the issue of nonmarital childbearing among black families in the United States, when the rate was one in three. Moynihan emphasized the declining economic prospects of men as an important factor leading black women to have births outside marriage. The social theories of the psychologist Clark (1965), the "Culture of Poverty" explanation of the anthropologist Lewis (1969), the "social isolation" theory of sociologist Wilson (1987), and more recently, the ethnographic account of Edin and Kefalas (2005), all highlight how growing up in an environment where there is little chance of social and economic advancement can lead young women to have babies outside of marriage. ${ }^{10}$

A number of studies have documented the relationship between background disadvantage and rates of early childbearing (for example, Duncan and Hoffman, 1990; An, Haveman, and Wolfe, 1993; Lundberg and Plotnick, 1995; Duncan, Yeung, Brooks-Gunn, and Smith, 1998). Girls who grow up in poverty or in a single-parent household are nearly twice as likely to have a

\footnotetext{
${ }^{10}$ Some of the explanations for teen childbearing seem too universal to explain the striking differences in rates of early nonmarital childbearing across socioeconomic groups, over time, or across states or countries. For example, developmental psychologists have suggested that teen childbearing is attributable to teens' stage of cognitive development, arguing that they are not quite ready to make the types of decisions that would prevent a pregnancy (Brooks-Gunn and Furstenberg, 1989; Hardy and Zabin, 1991; Brooks-Gunn and Paikoff, 1997). Behavioral economists O'Donohue and Rabin (1999) suggest that teens are "hyperbolic discounters" who place disproportionate weight on present happiness as compared to future well-being. But we doubt that the particularly high rate of teen childbearing among U.S. teens in certain states rather than others, or for U.S. teens as compared to their counterparts in Europe can be attributed to the more limited decision-making capacity-or more present-biased preferences - of the teenage brain at certain times or in certain places.
} 
teen birth as girls without these background disadvantage factors. We described differences by level of maternal education earlier. In an examination of cohort rates of early childbearing, we find that the proportion of a female cohort born economically disadvantaged—as captured by being born to a teen mother, a single mother, or to a mother with a low level of education - is tightly linked to the subsequent rate of early childbearing in that cohort (Kearney and Levine, 2010). But, strikingly, we find that state and year of birth fixed effects capture much of the variation. We interpret that finding as suggestive of the importance of some "cultural" dimension, which is largely unmodeled in the typical economics framework.

In recent work, we have sought to open this black box of fixed "cultural" differences across states and countries (Kearney and Levine, 2011). We consider how the economic circumstances in a place affect the decisions of girls growing up economically disadvantaged. One of our goals is to operationalize notions like "marginalization" and "hopelessness," emphasized in the anthropological and ethnographic research mentioned earlier, in a parsimonious economic model. Our model of early nonmarital childbearing rests on the notion that young women with limited opportunities to advance socially and economically-either through human capital investments or the marriage market — will be relatively more likely to choose early nonmarital childbearing, as compared to other women. This choice is modeled as a utility maximization problem based on a trade-off between the current period satisfaction associated with a baby and the potential long-term cost associated with foregone economic opportunities. The intuition is that if girls perceive their chances at long-term economic success to be sufficiently low, even if they do "play by the rules," then early childbearing is more likely to be chosen. We speculate that the combination of being poor and living in a more unequal (and less mobile) society contributes to a low perception of possible economic success, and hence 
leads to choices that favor short-term satisfaction - in this case, the decision to have a baby when young and unmarried.

Our main empirical analysis examines whether women with low socioeconomic status are more responsive to differences in the level of income inequality in terms of their childbearing and marital outcomes. We use individual-level data from the National Survey of Family Growth to look across U.S. states. We also use individual-level data from the Fertility and Family Survey, conducted by the United Nations, to look across a set of roughly a dozen developed countries. An illustrative example of the results of our analysis is provided in Figure 5, focusing on cross-state variation in teen births within the U.S. We use the level of education attained by the mother of each teen to separate them into different categories of socioeconomic status and then we divide the states into high-, middle-, and low-inequality categories based on the 50/10 ratio of household income (the ratio of the income at the median of the income distribution to the income at the $10^{\text {th }}$ percentile of the income distribution). Among teens with high socioeconomic status whose mothers attended college, we observe no difference in the likelihood of giving birth as a teen across these states, despite the reasonably large number of these women who do so. Among teens with lower socioeconomic status, though, there is a clear pattern of teen fertility across inequality categories. Teens in the highest-inequality states are roughly 5 percentage points more likely to give birth as a teen than teens in the lowest-inequality states. We find the opposite pattern when we focus on abortions as a teen-much less frequent abortions among teens with low socioeconomic status in high-inequality states - and no pattern like this when we repeat this exercise for sexual activity. We have also conducted a similar exercise at the county level and obtained similar results. We also obtain analogous results in a cross-country analysis. 
One potential concern in an analysis like this is that income inequality at the state level may be capturing any other state fixed factor that happens to be correlated with it, suggesting that inequality may not be the causal determinant of teen fertility. Although it is impossible to completely rule out this alternative, we have experimented with including other conditions that could lead to economic "despair," such as poverty concentration, the incarceration rate, and absolute levels of deprivation, and others. We also consider other potentially confounding factors that would be outside the proposed model, such as measures of state religiosity, political preferences, and a measure of social capital. None of these additional factors are found to alter the estimated relationship between inequality and teen fertility among women with low socioeconomic status.

Thus, we conclude that women with low socioeconomic status have more teen, nonmarital births when they live in higher-inequality locations, all else equal. The proximate mechanism driving this finding is that conditional on getting pregnant, more of these girls choose to carry their pregnancy to term. Indeed, our estimates suggest that income inequality can explain a sizable share of the geographic variation observed in the teen childbearing rate, on the order of 10 to 50 percent. We believe these results are consistent with the large body of work in other social science disciplines arguing that social marginalization and hopelessness are to blame for young, nonmarital childbearing. To the extent that greater levels of inequality are associated with a heightened sense of economic despair and marginalization, our empirical findings support this claim. Certainly, additional research into this link is warranted. This explanation is one of the first that has the potential to explain any sizable share of the geographic variation in teen childbearing. 


\section{Teen ChILdBearing as CAUSE OR EFFect?}

A premise of most public discussions about teen fertility is that having a baby as a teen leads to inferior outcomes for the mother and the child. Indeed, women who give birth during their teenage years are more likely than other women to drop out of high school, to remain unmarried, and to live in poverty. The children of teenage mothers fare worse than other children on economic, social, and cognitive dimensions (Hoffman and Maynard, 2008). If teen childbearing causes large adverse consequences, then the natural response is to consider policies that can potentially reduce the likelihood of a teen pregnancy: sex education, abstinence promotion, improved contraceptive access, and related interventions. Kearney (2010) reviews the evidence on the effectiveness of various teen pregnancy prevention programs. Alternatively, however, it could be that outside factors may cause both a teen to give birth and to have inferior outcomes. For example, if those who lack economic opportunity are more likely to give birth as a teen, they and their children are likely to have inferior outcomes regardless of when they give birth. Providing free contraception, for instance, could (modestly) reduce the likelihood of giving birth as a teen, but it does not alter the underlying calculus that leads disadvantaged women to "drop out" of the mainstream climb toward economic and social prosperity — the path of completing school, investing in human capital, and putting marriage before motherhood.

This section reviews the most compelling evidence to date on whether teen childbearing itself causes adverse outcomes for teen mothers and their children. ${ }^{11}$ We also review a related, important issue regarding "unintended" pregnancies. A large share of teen (and nonmarital) births are reported by the mother to be "unintended," which would suggest that providing teens with better access to sex education, contraception, and related policies could help them achieve

\footnotetext{
${ }^{11}$ A separate question is the extent to which teen childbearing causes adverse outcomes for society more broadly. This is a topic that has been addressed by others (see Hoffman and Maynard, 2008, for a recent review), although this literature has struggled with the issue of credibly identifying causal effects.
} 
their "intended" goal of not becoming pregnant. However, we believe that many births that are labeled as "unintended" actually reflect a degree of ambivalence on the part of the teen mother, in which case the policy prescription is less clear.

\section{A. The Effect of Teen Childbearing on Mothers and their Children}

To what extent are the inferior outcomes of teen mothers driven by the event of having given birth as a teenager, as opposed to other factors, such as growing up in disadvantaged circumstances? A comparison of the outcomes of women who did and who did not give birth as teens is inherently biased by selection effects: teenage girls who "select" into becoming pregnant and subsequently giving birth (as opposed to choosing abortion) are different in terms of their background characteristics and potential future outcomes than teenage girls who delay childbearing.

We know that girls who grow up in poverty are more likely to become pregnant and to give birth as teenagers. Tabulating data from the 2003 Panel Study of Income Dynamics, we report that in a sample of women age 20 to 35,24 percent give birth before age 20; but among the subsample of those women who were born into poverty, 49 percent give birth before age 20 . (Kearney and Levine 2010)

A number of authors have tried to isolate the causal effect of teenage childbearing on subsequent outcomes, holding constant family background characteristics. To isolate the effect of teen childbearing, Geronimus and Korenman (1992) employ a "within-family" estimation approach that compares differences in subsequent socioeconomic status of sisters who experienced their first births at different ages. They analyze samples from three datasets: the National Longitudinal Survey Young Women's Sample (NLSYW), the Panel Study of Income Dynamics (PSID), and the 1979 National Longitudinal Survey of Youth (NLSY79). They find 
that cross-sectional comparisons that do not control for detailed family background greatly overstate the costs of teen childbearing. In fact, once background characteristics are controlled for, the differences are quite modest. Furthermore, even these modest differences likely overstate the costs of teen childbearing, since the sister who gives birth as a teen is likely to be "negatively" selected compared to her sister who does not.

In addition to differences in observed and unobserved family background characteristics, girls who are more committed to achieving higher levels of educational attainment and economic success may be more committed to preventing a pregnancy from occurring during their teenage years. Such girls may also be more inclined to choose abortion if they do get pregnant. From a research perspective, we ideally want to observe a sample of women who have the same potential outcomes and the same inclination to get pregnant and give birth, but by random chance, some do and some do not become teen mothers. A number of papers attempt to exploit quasi-experimental variation in who becomes a teen mother to isolate the causal consequences of teen childbearing.

Hotz, Mullen, and Sanders (1997) and Hotz, McElroy, and Sanders (2005) exploit the fact that some women who become pregnant as teenagers experience a miscarriage and thus do not have a birth. Their strategy essentially identifies the effect of delaying childbearing for women who become pregnant as teenagers. Using data from the 1979 National Longitudinal Survey of Youth (NLSY79) on women who were aged 13 to 17 between 1971 and 1982, the authors begin by replicating previous findings of a correlation between teen childbearing and later life outcomes. ${ }^{12}$ But when the authors of these studies employ their miscarriages

\footnotetext{
${ }^{12}$ An interesting statistic they tabulate in their data is that among women who become pregnant before age 18 , those who choose to end their pregnancy in abortion on average have family incomes that are 40 percent higher than those who give birth. This supports the claim that among pregnant teens, there are important selection effects driving the decision to become a teen mother.
} 
"experiment," and thereby avoid confounding selection effects, none of the differences are statistically significant, and some are even reversed in sign. Hoffman (2008) reexamines this data and finds that the estimated impacts of a teen birth are more negative for teen mothers who had births in the early 1980 s relative to 1970 s. ${ }^{13}$ Ribar (1994) also employs an instrumental variables framework using the NLSY79 data. He uses age at menarche in an instrumental variables framework, noting that earlier age at menarche leads to more years at risk of becoming pregnant. The negative consequences of teen birth for high school completion rate also seem to disappear with this instrumental variable approach.

David Levine and Gary Painter (2003) use a within-school propensity-score matching estimator-using quantitative methods to "match" individuals with an equal propensity to give birth as a teen and then comparing outcomes for those matched pairs who differ in teen childbearing outcomes - to identify causal effects on educational attainment. They use data from the 1988 National Educational Longitudinal Survey. The authors view their findings as suggesting (p. 898) that a "substantial portion of the relation between teen childbearing and high school completion is due to preexisting disadvantages of the young women, not due to the childbirth itself ... Thus, half or more of the young mother's disadvantages would not have been eliminated by the young women waiting until their twenties to have children."

The evidence regarding the outcomes for the children of teen mothers similarly finds that observed differences reflect selection on the part of who becomes a teen mother, not the negative consequences of teen childbearing itself. Geronimus, Korenman, and Hillemeier (1994) employ a "within family" estimation strategy that compares outcomes for first cousins born to sisters of

\footnotetext{
${ }^{13}$ Ashcraft and Lang (2010) build on the Hotz et al. study using data from the 1995 wave of the NSFG, which they argue is better suited for measuring pregnancy outcomes than the NLSY79. They additionally adjust for the fact that some girls will abort their pregnancy before a miscarriage occurs, leading to a selected sample. Their empirical estimates suggest that the effects of teen childbearing are more negative than suggested by Hotz, McElroy, and Sanders (2005), but that the adverse consequences on socioeconomic outcomes are quite small in magnitude.
} 
different ages. This analysis finds that children of teen mothers appear to score no worse on measures of development than their first cousins whose mothers had first births after their teen years. A more recent paper by Mullin (2005) employs the empirical approach of Hotz, Mullin, and Sanders (1997) - a bounded instrumental variables treatment framework relying on the occurrence of "miscarriages"- to assess the effect of teen childbearing on children. His analysis finds that delaying childbearing for nonblack teen mothers actually leads to inferior outcomes for the children. Building on the literature, Sepulveda (2010) extends the Ashcraft and Lang (2010) approach to the case of children. He estimates the causal effect of teen childbearing on children's outcomes to be a tightly bounded zero. Our reading of the most rigorous empirical studies to date is that the data reject the hypothesis that the children of teenage mothers would have experienced better outcomes had those same mothers delayed pregnancy until after age 19.

Taken as a whole, previous research has had considerable difficulty finding much evidence in support of the claim that teen childbearing has a causal impact on mothers and their children. Instead, at least a substantial majority of the observed correlation between teen childbearing and inferior outcomes is the result of underlying differences between those who give birth as a teen and those who do not.

\section{B. Intendedness}

In 1994 and 2001, respectively, 77 percent and 82 percent of teen pregnancies were reported as "unintended." Indeed, among all women of childbearing age, half of all pregnancies are reported to be unintended (Finer and Henshaw, 2006). Unintended pregnancies are related to a host of inferior outcomes for mothers and children, including higher rates of low birth weight and infant mortality, depression, and domestic violence, among others (Brown and Eisenberg, 1995). 
However, interpreting these statistics is difficult (Trussell, Vaughan, and Stanford, 1999; Santelli et al., 2003). The common sources for pregnancy "intention" are the National Survey of Family Growth (NSFG) and the Pregnancy Risk Assessment Monitoring System (PRAMS). A first difficulty is that the questions about intention are asked retrospectively: the NSFG asks the question after the child is born and the PRAMS asks the question when the woman is pregnant. For women in their $20 \mathrm{~s}$, a common belief in the research community is that too few births get reported as "unintended," because after women have become pregnant and given birth they view the event as a happy one. In fact, Joyce, Kaestenr, and Korenman (2002) report that it is not uncommon for reported pregnancy intentions to change between the time of the pregnancy to a period after the child was born, with more women changing towards a more positive assessment than the reverse. When one focuses on teen fertility, we would argue that it is not generally socially acceptable to report that you "wanted" to get pregnant as a teenager, either at the time of conception, after pregnancy, or after the child is born. So survey rates of "unintendedness" would be biased upward.

Reports of pregnancy intendedness also contain inconsistencies that are hard to reconcile. Trussell, Vaughan, and Stanford (1999), for instance, report that one-third of women who report that their pregnancies began with a contraceptive failure also reported that the pregnancy was intended. Moreover, 41 percent of those who reported a contraceptive failure that led to an unintended pregnancy also report that they were happy about their pregnancy.

A plausible interpretation here is that "intendedness" is not a dichotomous variable, but instead reflects a continuum. A woman may not have planned in advance to become pregnant, but she may have been ambivalent towards whether a pregnancy might occur. 
We use data from the Behavioral Risk Factor Surveillance System to tabulate why some sexually active women report not using birth control. We are interested in gaining some insight into whether unintended pregnancies are more often associated with unwantedness as opposed to ambivalence. In addition, we hope to gain some insight into how often limited information or limited access to contraception is to blame for a would-be unintended pregnancy. The purpose of these data is to track health outcomes and risky behaviors for adults (age 18 and over). We identify a sample of 230 women age 18 and 19 in the 2002 and 2004 surveys who are sexually active, unmarried, and not using birth control. Only 15 percent report that were not expecting to have sex, and 11 percent report that they did not think that they could become pregnant. Remarkably, only 2 percent report that they could not afford birth control. In fact, 20 percent of them report that they either want to get pregnant or do not care if they get pregnant. The most common answer by far -45 percent — that women gave for not using birth control is "other reason." Although these findings pertain specifically to older teens, our interpretation of these data at least for this age group is that the non-use of contraception among these sexually active women reflects to a large degree a general sense of ambivalence toward becoming pregnant.

Hohmann-Marriott (2011) investigates the concept of ambivalence by comparing a woman's report of what she labels attitudes, behavior, and emotion using data from the Early Childhood Longitudinal Study—Birth Cohort (ECLS-B). "Attitudes" reflect standard wantedness and timing questions. "Behavior" addresses contraceptive use and reasons for nonuse. "Emotions" address happiness towards the birth. She defines ambivalence towards a birth based on contradictory answers to the categories of questions. For instance, a woman whose pregnancy was categorized as unintended, but who did not use contraception prior to pregnancy is defined to have been ambivalent towards the pregnancy. Overall, Hohmann-Marriott finds that 
39 percent of births reflect ambivalence on the part of the mother, as compared to much lower rates of 13 percent being truly unintended. However, these data only include women who gave birth, and who are more inclined towards positive intentions than a sample of all pregnancies because many unintended pregnancies end in abortion.

Our reading of the evidence is that ambivalence towards a pregnancy is reasonably common. Ambivalence toward pregnancy has very different policy implications than unwantedness. ${ }^{14}$

\section{Discussion}

We believe that the high rate of teen childbearing in the United States matters because it is a marker of a social problem, rather than the underlying social problem itself. If a teenager has a baby because her life chances seem so limited that her life will not be any better if she delays childbearing, then teen childbearing is unlikely to be causing much of a detrimental effect. Our review of the evidence is consistent with this position.

We have focused here on the determinants and consequences of teen motherhood in the U.S. One thing that we have not done is explain the dramatic decline in teen childbearing in the United States over the past 20 years. Although we believe that inequality and lack of opportunity explains a substantial share of the geographic variation in teen childbearing, it is not a candidate explanation for the downward trend in the United States over the past two decades, primarily because the $50 / 10$ ratio that we rely on as a measure of inequality has not changed much during this period (although our results are insensitive to the specific measure used). ${ }^{15}$ In the recent analysis we completed investigating recent trends that we described briefly earlier (Kearney and

\footnotetext{
${ }^{14}$ For an alternative interpretation, see Kaye, Suellentrop, and Sloup (2009).

${ }^{15}$ Other indicators of inequality like the $90 / 50$ ratio (the ratio of the income at the 90th percentile to that at the median) have risen; but that would predict an upward trend in teen childbearing.
} 
Levine, 2012), we conclude that most targeted policies had no effect on teen birth rates. The two policy changes that do seem to matter some, expanded family planning services through Medicaid and reduced welfare benefits can only combine to explain 12 percent of the decline in teen childbearing between 1991 and 2008. Demographic changes - in particular, the increasing Hispanic share of the teenage population - also cannot explain the recent decline, and in fact, would seem to have worked to increase teen childbearing rates. Additional work to understand the causes of the decline in U.S. teen childbearing should be a priority for future research.

Another issue related to teen childbearing is the consequences of nonmarital childbearing at any age. Single mothers have high poverty rates as well and the vast majority ( 87 percent in 2008; Martin et al. 2010) of teen births are nonmarital births. According to 2006 Census figures, 5.7 percent of people living in married couple families live below the federal poverty threshold as compared to 30.5 percent of people living in female-headed households. Broader discussions of nonmarital fertility, however, are complicated by the disparate types of women who encounter this outcome. Even among women beyond their teen years, 35.2 percent of births are to unmarried women. In fact, women in their teens represent 10 percent of all women giving birth; the number of nonmarital births to nonteens is three times larger than the number of teen nonmarital births. Clearly, these older women face different issues. It is a separate, complex issue to determine how much better off women and children would be if policies could successfully increase rates of two-parent biological families among economically disadvantaged populations. 


\section{REFERENCES}

Akerlof, George A., Janet L. Yellen, and Michael L Katz. 1996. "An Analysis of Out-ofWedlock Childbearing in the United States." Quarterly Journal of Economics 111(2): 277-317.

An, Chong-Bum, Robert Haveman, and Barbara Wolfe. 1993. "Teen Out-of-Wedlock Births and Welfare Receipt: The Role of Childhood Events and Economic Circumstances." Review of Economics and Statistics 75(2): 195-208.

Ashcraft, Adam, and Kevin Lang. 2010. "The Consequences of Teenage Childbearing: Consistent Estimates when Abortion Makes Miscarriage Nonrandom." Unpublished manuscript.

Becker, Gary S., and H. Gregg Lewis. 1973. "On the Interaction between the Quantity and Quality of Children.” Journal of Political Economy 81(2): S279-S288.

Boonstra, Heather. 2002. "Teen Pregnancy: Trends and Lessons Learned." Guttmacher Report on Public Policy 5(1): 7-10.

Brooks-Gunn, Jeanne, and Frank F. Furstenberg, Jr. 1989. "Adolescent Sexual Behavior." American Psychologist 44(2): 249-57.

Brooks-Gunn, Jeanne, and Roberta Paikoff. 1997. "Sexuality and Developmental Transitions during Adolescence." In Health Risks and Developmental Transitions during Adolescence, edited by John Schulenberg, Jennifer L. Maggs, and Klaus Hurrelmann, 190-245. Cambridge, UK: Cambridge University Press.

Brown, Sarah, and Leon Eisenberg, eds. 1995. The Best Intentions: Unintended Pregnancy and the Well-Being of Children and Families. Washington, DC: Institute of Medicine.

Clark, Kenneth B. 1965. Dark Ghetto: Dilemmas of Social Power. New York: Harper \& Row.

Darroch, Jacqueline E., Susheela Singh, Jennifer J. Frost, and the Study Team. 2001. "Differences in Teenage Pregnancy Rates among Five Developed Countries: The Roles of Sexual Activity and Contraceptive Use." Family Planning Perspectives 33(6): 244-50, 281.

Duncan, Greg J., and Saul D. Hoffman. 1990."Welfare Benefits, Economic Opportunities, and Out-of-Wedlock Births among Black Teenage Girls.” Demography 27(4): 519-36.

Duncan, Greg J, W. Jean Yeung, Jeanne Brooks-Gunn, and Judith R. Smith. 1998. "How Much Does Childhood Poverty Affect the Life Chances of Children?" American Sociological Review 63(3): 406-23.

Edin, Kathryn, and Maria Kefalas. 2005. Promises I Can Keep: Why Poor Women Put Motherhood before Marriage. Berkeley, CA: University of California Press.

Finer, Lawrence B., and Stanley K. Henshaw. 2006. "Disparities in Rates of Unintended Pregnancy in the United States." Perspectives on Sexual and Reproductive Health 38(2): 90-96. 
Geronimus, Arline T., and Sanders Korenman. 1992. “The Socioeconomic Consequences of Teen Childbearing Reconsidered.” Quarterly Journal of Economics 107(4): 1187-1214.

Geronimus, Arline T., and Sanders Korenman. 1993. "The Socioeconomic Costs of Teen Childbearing: Evidence and Interpretation.” Demography 30(2): 281-90.

Geronimus, Arline T., Sanders Korenman, and Marianne M. Hillemeier. 1994. "Does Young Maternal Age Affect Child Development? Evidence from Cousin Comparisons in the United States." Population and Development Review 20(3): 585-609.

Godeau, Emannuelle, Saoirse Nic Gabhainn, Céline Vignes, Jim Ross, Will Boyce, and Joanna Todd. 2008. "Contraceptive Use by 15 Year Old Students at the Last Sexual Intercourse." Archives of Pediatric \& Adolescent Medicine 162(1): 66-73.

Grogger, Jeffrey, and Lynn A. Karoly. 2005. Welfare Reform: Effects of a Decade of Change. Cambridge, MA: Harvard University Press.

Guttmacher Institute. 2010. U.S. Teenage Pregnancies, Births and Abortions: National and State Trends and Trends by Race and Ethnicity. New York: Guttmacher Institute.

Hamilton, Brady E., Joyce A. Martin, and Stephanie J. Ventura. 2010. "Births: Preliminary Data for 2009." National Vital Statistics Report, December 21, 59(3).

Hardy, Janet B., and Laurie Schwab Zabin. 1991. Adolescent Pregnancy in an Urban Environment. Washington, DC: Urban Institute Press.

Hoffman, Saul D. 2008. "Updating the Teen Miscarriage Experiment: Are the Effects of a Teen Birth Becoming More Negative?" Working Papers 08-08, University of Delaware, Department of Economics.

Hoffman, Saul D., and Rebecca A. Maynard, eds. 2008. Kids Having Kids: Economic Costs and Social Consequences of Teen Pregnancy. Washington, DC: Urban Institute.

Hohmann-Marriott, Bryndl. 2011. "Ambivalent Intentions for Pregnancy: Measurement, Partner Effects, and Future Intentions." Presented at the 2011 meeting of the Population Association of America.

Hotz, V. Joseph, Susan Williams McElroy, and Seth Sanders. 2005. "Teenage Childbearing and Its Life Cycle Consequences: Exploiting a Natural Experiment." Journal of Human Resources 40(3): 683-715.

Hotz, V. Joseph, Charles Mullin, and Seth Sanders. 1997. "Bounding Causal Effect Using Data from a Contaminated Natural Experiment: Analyzing the Effects of Teenage Childbearing." Review of Economic Studies 64(4): 575-603. 
Joyce, Ted, Robert Kaestner, and Sanders Korenman. 2002. "On the Validity of Retrospective Assessments of Pregnancy Intention.” Demography 39(1): 199-213.

Kaye, Kelleen, Katherin Suellentrop, and Corinna Sloup. 2009. The Fog Zone: How Misperceptions, Magical Thinking, and Ambivalence Put Young Adults at Risk for Unplanned Pregnancy. Washington, DC: National Campaign to Prevent Teen and Unplanned Pregnancy.

Kearney, Melissa S. 2004. "Is There an Effect of Incremental Welfare Benefits on Fertility Behavior? A Look at the Family Cap." Journal of Human Resources 39(2): 295-325.

Kearney, Melissa S. 2010. "Teen Pregnancy Prevention." Chap. 8 in Targeting Investments in Children: Fighting Poverty when Resources are Limited, edited by Phillip B. Levine and David J. Zimmerman. University of Chicago Press.

Kearney, Melissa S., and Phillip Levine. 2009. "Subsidized Contraception, Fertility, and Sexual Behavior." Review of Economics and Statistics 91(1): 137-51.

Kearney, Melissa S., and Phillip B. Levine. 2010. "Socioeconomic Disadvantage and Early Childbearing." Chap. 6 in The Problems of Disadvantaged Youth: An Economic Perspective, edited by Jonathan Gruber. University of Chicago Press.

Kearney, Melissa S., and Phillip B. Levine. 2011. "Income Inequality and Early, Non-marital Childbearing: An Economic Exploration of the "Culture of Despair."' NBER Working Paper 17157.

Kearney, Melissa S. and Phillip B. Levine. 2012. "Explaining Recent Trends in the U.S. Teen Birth Rate.” NBER Working Paper 17964.

Levine, David I., and Gary Painter. 2003. "The Schooling Costs of Teenage Out-of-Wedlock Childbearing: Analysis with a Within-School Propensity-Score Matching Estimator." Review of Economics and Statistics 85(4): 884-900.

Levine, Phillip B. 2002. "The Impact of Social Policy and Economic Activity throughout the Fertility Decision Tree.” NBER Working Paper 9021.

Levine, Phillip B. 2004. Sex and Consequences: Abortion, Public Policy, and the Economics of Fertility. Princeton, NJ: Princeton University Press.

Levine, Phillip B., and David J. Zimmerman, eds. 2010. Targeting Investments in Children: Fighting Poverty when Resources are Limited. University of Chicago Press.

Lewis, Oscar. 1969. "The Culture of Poverty." In On Understanding Poverty: Perspectives from the Social Sciences, edited by Daniel P. Moynihan, 187-200. New York: Basic Books. 
Lundberg, Shelly, and Robert D. Plotnick. 1995. "Adolescent Premarital Childbearing: Do Economic Incentives Matter?” Journal of Labor Economics 13(2): 177-200.

Martin, Joyce A., Brady E. Hamilton, Paul D. Sutton, Stephanie J. Ventura, T. J. Mathews, and Michelle Osterman. 2010. Births: Final Data for 2008. National Vital Statistics Reports vol. 59, no. 1.

Martin, Joyce A., Brady E. Hamilton, Stephanie J. Ventura, Michelle J. K. Osterman, Sharon Kirmeyer, T. J. Mathews, and Elizabeth C. Wilson. 2011. Births: Final Data for 2009. National Vital Statistics Reports, vol. 60, no. 1.

Moffitt, Robert A. 1998. "The Effect of Welfare on Marriage and Fertility: What Do We Know and What Do We Need to Know?" Chap. 4 in Welfare, the Family, and Reproductive Behavior, edited by R. Moffitt. Washington: National Research Council, National Academy of Sciences Press.

Moffitt, Robert A. 2003. "The Negative Income Tax and the Evolution of U.S. Welfare Policy." Journal of Economic Perspectives 17(3): 119-40.

Mullin, Charles. 2005. "Bounding Treatment Effects with Contaminated and Censored Data: Assessing the Impact of Early Childbearing on Children." Advances in Economic Analysis \& Policy 5(1): Article 8.

O’Donoghue, Ted, and Matthew Rabin. 1999. "Doing It Now or Later." American Economic Review 89(1): 103-124.

Ribar, David C. 1994. "Teenage Fertility and High School Completion." Review of Economics and Statistics 76(3): 413-24.

Santelli, John S., Laura Duberstein Lindberg, Lawrence B. Finer, and Susheela Singh. 2007. "Explaining Recent Declines in Adolescent Pregnancy in the United States: The Contribution of Abstinence and Improved Contraceptive Use." American Journal of Public Health 97(1): 15056.

Santelli, John, Roger Rochat, Kendra Hatfield-Timajchy, Brenda Colley Gilbert, Kathryn Curtis, Rebecca Cabral, Jennifer S. Hirsch, and Laura Schieve. 2003. "The Measurement and Meaning of Unintended Pregnancy." Perspectives on Sexual and Reproductive Health 35(2): 94-101.

Santelli, John, Theo Sandfort, and Mark Orr. 2008. "Transnational Comparisons of Adolescent Contraceptive Use." Archives of Pediatric and Adolescent Medicine 162(1): 92-94.

Sedgh, Gilda, Stanley K. Henshaw, Susheela Singh, Akinrinola Bankole, and Joanna Drescher. 2007. "Legal Abortion Worldwide: Incidence and Recent Trends." International Family Planning Perspectives 33(3): 106-116. 
Sepulveda, Carlos Eduardo. 2010. "Teenage Childbearing: Effects on the Child." Unpublished manuscript.

Trussell, James, Barbara Vaughan, and Joseph Stanford. 1999. "Are All Contraceptive Failures Unintended Pregnancies? Evidence from the 1995 National Survey of Family Growth." Family Planning Perspectives 31(5): 246-47, 260.

United Nations, Department of Economic and Social Affairs. 2011. United Nations Demographic Yearbook, 2009-2010. New York: United Nations.

http://unstats.un.org/unsd/demographic/products/dyb/dybsets/2009-2010.pdf.

United Nations Economic Commission for Europe (UNECE). UNECE Statistical Database. Available at http://w3.unece.org/pxweb/. Accessed June 1, 2011.

U.S. Department of Labor, Office of Policy Planning and Research. 1965. The Negro Family: The Case for National Action. Washington, DC: United States Department of Labor.

Wilson, William Julius. 1987. The Truly Disadvantaged: The Inner City, the Underclass and Public Policy. Chicago: University of Chicago Press. 
Table 1: Teen Birth Rates per 1000 Females Age 15-19, 2009

\begin{tabular}{|c|c|c|c|c|c|}
\hline State & $\begin{array}{l}\text { Teen birth } \\
\text { rate }\end{array}$ & State & $\begin{array}{l}\text { Teen birth } \\
\text { rate }\end{array}$ & State & $\begin{array}{l}\text { Teen birth } \\
\text { rate }\end{array}$ \\
\hline \multicolumn{2}{|l|}{ Low } & \multicolumn{2}{|c|}{ Moderate } & \multicolumn{2}{|c|}{ High } \\
\hline New Hampshire & 16.4 & Michigan & 32.7 & North Carolina & 44.9 \\
\hline Vermont & 17.4 & Oregon & 33.1 & Wyoming & 45.0 \\
\hline Massachusetts & 19.6 & Nebraska & 34.6 & Nevada & 47.4 \\
\hline Connecticut & 21.0 & Delaware & 35.3 & Washington, DC & 47.7 \\
\hline New Jersey & 22.7 & Idaho & 35.9 & Georgia & 47.7 \\
\hline Minnesota & 24.3 & Illinois & 36.1 & South Carolina & 49.1 \\
\hline Maine & 24.4 & California & 36.6 & West Virginia & 49.8 \\
\hline New York & 24.4 & South Dakota & 38.4 & Arizona & 50.6 \\
\hline Rhode Island & 26.8 & Colorado & 38.5 & Tennessee & 50.6 \\
\hline North Dakota & 27.9 & Montana & 38.5 & Alabama & 50.7 \\
\hline Pennsylvania & 29.3 & Ohio & 38.9 & Kentucky & 51.3 \\
\hline Wisconsin & 29.4 & Florida & 39.0 & Louisiana & 52.7 \\
\hline Utah & 30.7 & Hawaii & 40.9 & Arkansas & 59.2 \\
\hline Virginia & 31.0 & Missouri & 41.6 & Oklahoma & 60.1 \\
\hline Maryland & 31.3 & Indiana & 42.5 & Texas & 60.7 \\
\hline Washington & 31.9 & Kansas & 43.8 & New Mexico & 63.9 \\
\hline Iowa & 32.1 & Alaska & 44.5 & Mississippi & 64.2 \\
\hline
\end{tabular}

Source: Martin, et al. (2011). 
Table 2: Rates of Pregnancy, Birth, and Abortion across Countries and States in the United States

\begin{tabular}{lcccc}
\hline \hline & $\begin{array}{c}\text { Pregnancy rate } \\
\text { (per 1,000) }\end{array}$ & $\begin{array}{c}\text { Birth rate } \\
\text { (per 1,000) }\end{array}$ & $\begin{array}{c}\text { Abortion rate } \\
\text { (per 1,000) }\end{array}$ & $\begin{array}{c}\text { \% of pregnancies } \\
\text { aborted }\end{array}$ \\
\hline Denmark (2003) & 24 & 5 & 15 & 63.2 \\
Germany (2003) & 23 & 12 & 7 & 31.1 \\
New Hampshire (2005) & 33 & 18 & 11 & 33.3 \\
United Kingdom (2003) & 59 & 27 & 23 & 38.8 \\
United States (2005) & 70 & 40 & 19 & 27.1 \\
Mississippi (2005) & 85 & 61 & 11 & 12.9 \\
\hline \hline
\end{tabular}

Sources: State data are from Guttmacher Institute (2010). International birth data are from the UNECE statistical database. International abortion data are from Sedgh, Henshaw, Singh, Bankole, and Drescher (2007). 
Table 3: Mechanical Correlations with Teen Fertility (standard errors in parentheses)

\begin{tabular}{|c|c|c|c|}
\hline $\begin{array}{l}\text { \% Any sexual activity } \\
\text { in past } 3 \text { months }\end{array}$ & $\begin{array}{c}0.162 \\
(0.017)\end{array}$ & $\begin{array}{l}\text { \% Any sexual activity } \\
\text { in past } 3 \text { months }\end{array}$ & $\begin{array}{c}0.151 \\
(0.019)\end{array}$ \\
\hline \multirow[t]{4}{*}{$\begin{array}{l}\% \text { Used any contraception } \\
\text { if sexually active }\end{array}$} & $\begin{array}{l}-0.186 \\
(0.030)\end{array}$ & $\begin{array}{l}\% \text { Used pill } \\
\text { if sexually active }\end{array}$ & $\begin{array}{l}-0.156 \\
(0.028)\end{array}$ \\
\hline & & $\begin{array}{l}\% \text { Used condom } \\
\text { if sexually active }\end{array}$ & $\begin{array}{l}-0.120 \\
(0.023)\end{array}$ \\
\hline & & $\begin{array}{l}\text { \% Used Depo or other } \\
\text { if sexually active }\end{array}$ & $\begin{array}{l}-0.018 \\
(0.043)\end{array}$ \\
\hline & & $\begin{array}{l}\% \text { Used withdrawal } \\
\text { if sexually active }\end{array}$ & $\begin{array}{c}0.022 \\
(0.062)\end{array}$ \\
\hline$R^{2}$ & 0.64 & $R^{2}$ & 0.71 \\
\hline $\begin{array}{l}\text { Number of } \\
\text { States/Years }\end{array}$ & 167 & $\begin{array}{l}\text { Number of } \\
\text { States/Years }\end{array}$ & 167 \\
\hline
\end{tabular}

Source: Authors using data from the Youth Risky Behavior Surveillance survey and teen birth rates by state/year from Vital Statistics data.

Notes: We estimate regression models of the state-year teen birth rate as a function of measures of sexual activity and contraceptive use by state-year. The dependent variable in each model is the probability of giving birth as a teen in a year. The independent variables are share of teenagers in a state in a given year who have engaged in sexual activity in the previous three months along with measures of alternative contraceptive choices. All regressions are weighted by the population of women age 15 to 19 in each state/year. Withdrawal is counted as a form of contraception. 
Figure 1: International Comparison of Teen Birth Rates, 2009

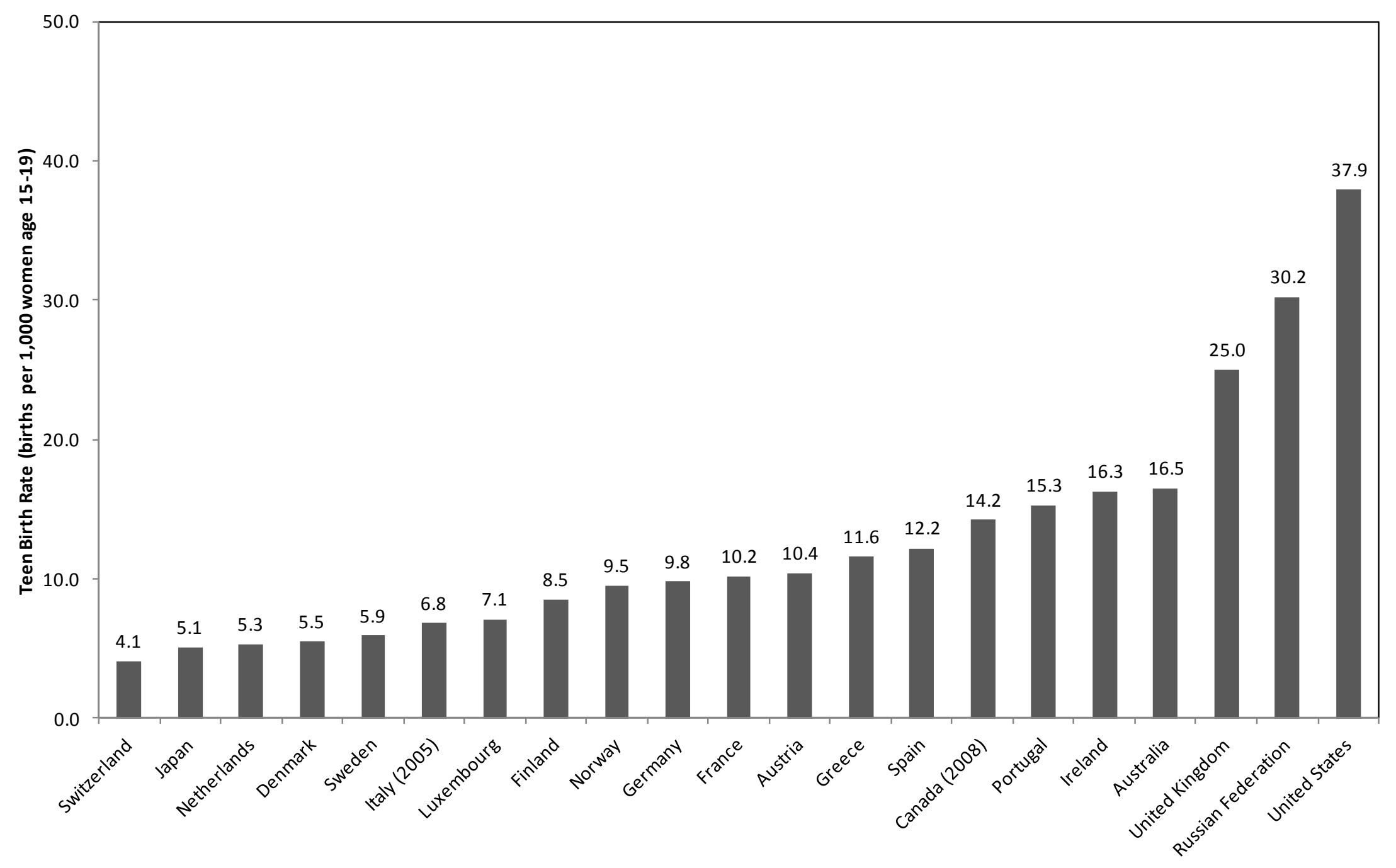

source: UNECEStatistical Database and UN Demographic Yearbook, 2009. 


\section{Figure 2: Trends in the Teen Pregancy, Abortion, and Birth Rate}

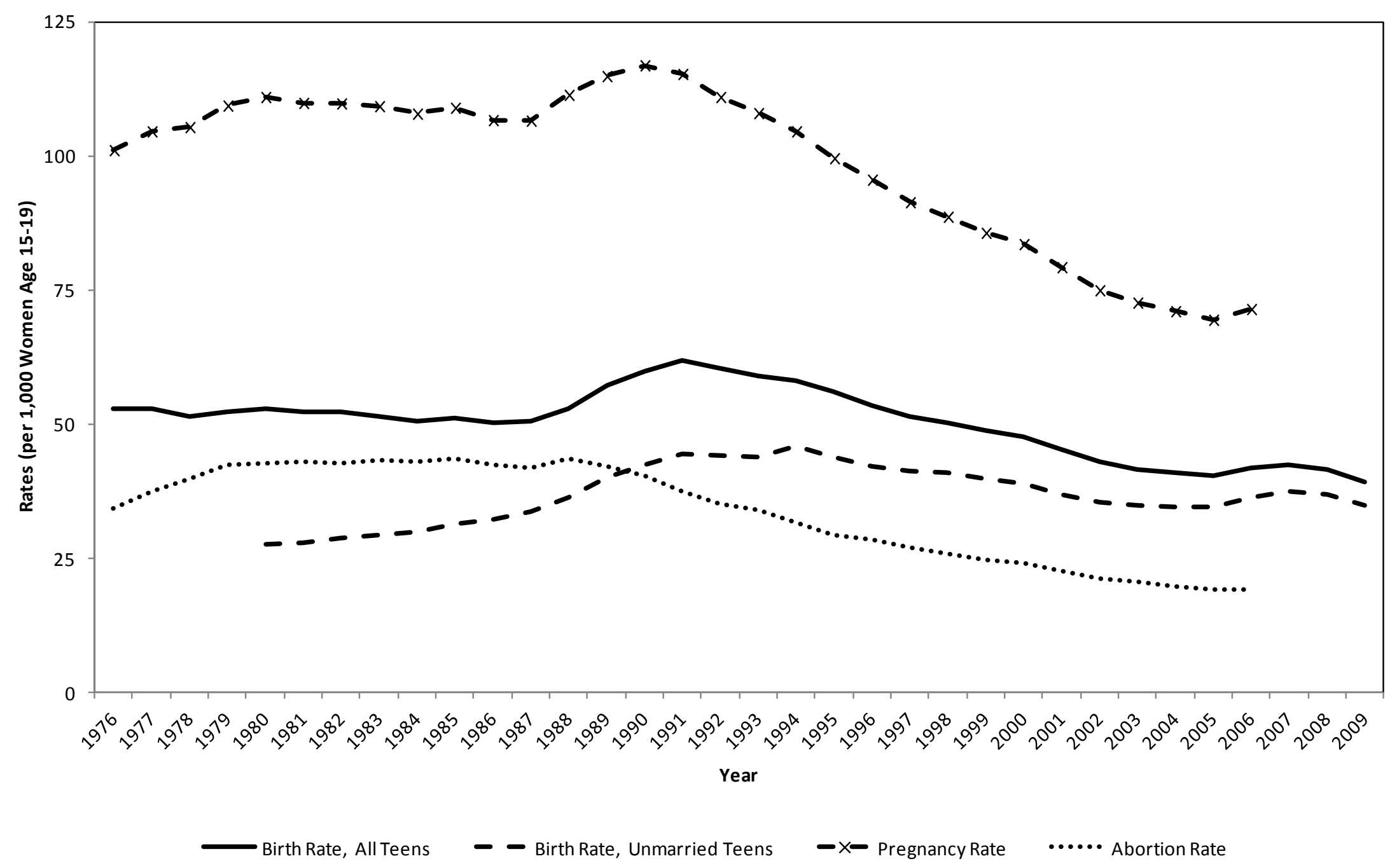

source: Martin, et al. (2010) and Hamilton, et al. (2010), and Guttmacher Institute, 2010. 


\section{Figure 3: Trends in the Teen Birth Rate by Race/Ethnicity}

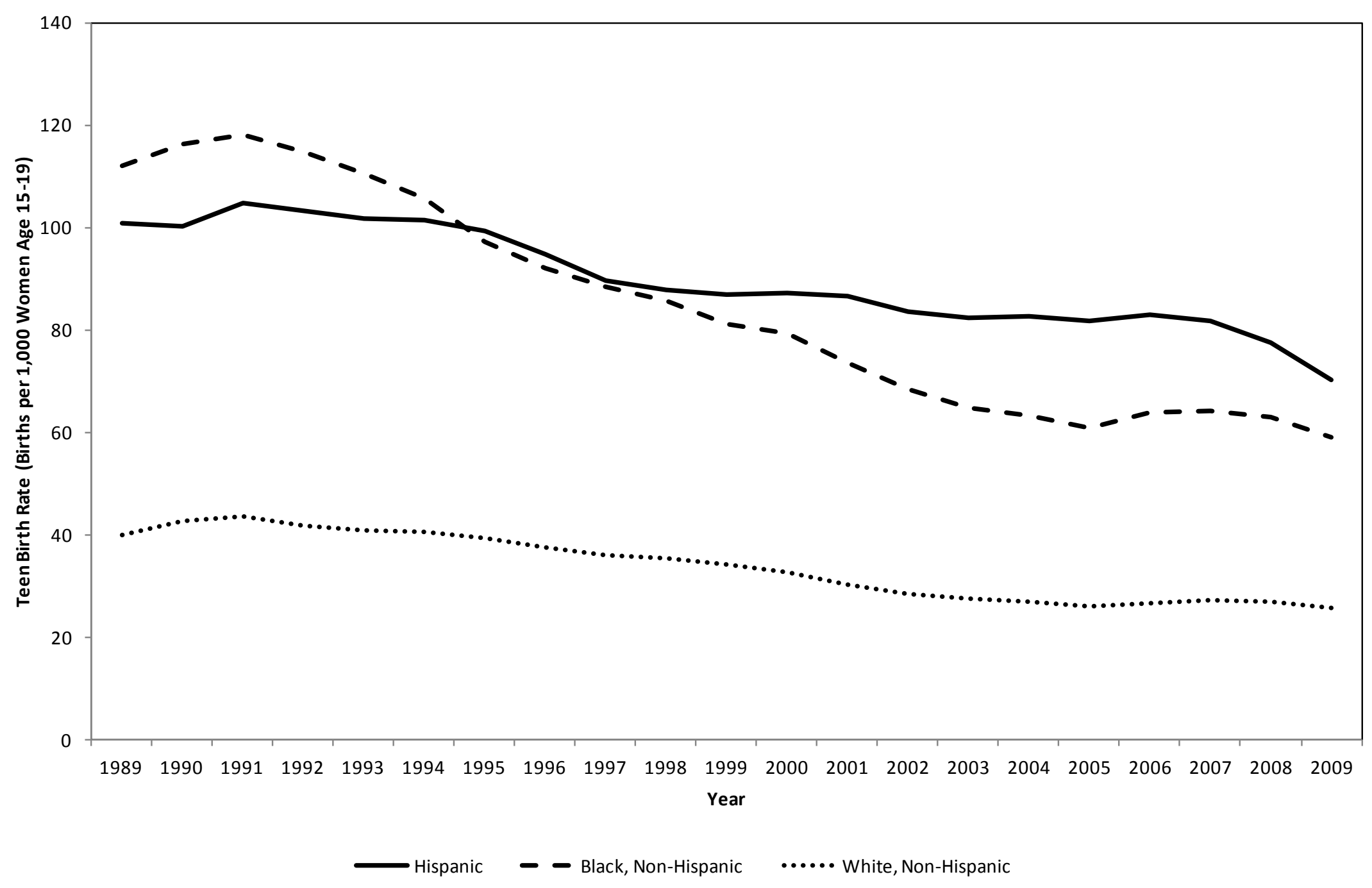

source: Martin, et al. (2011). 
Figure 4: Rates of Sexual Activity and Contraceptive Use among School-Aged (14-18) Girls

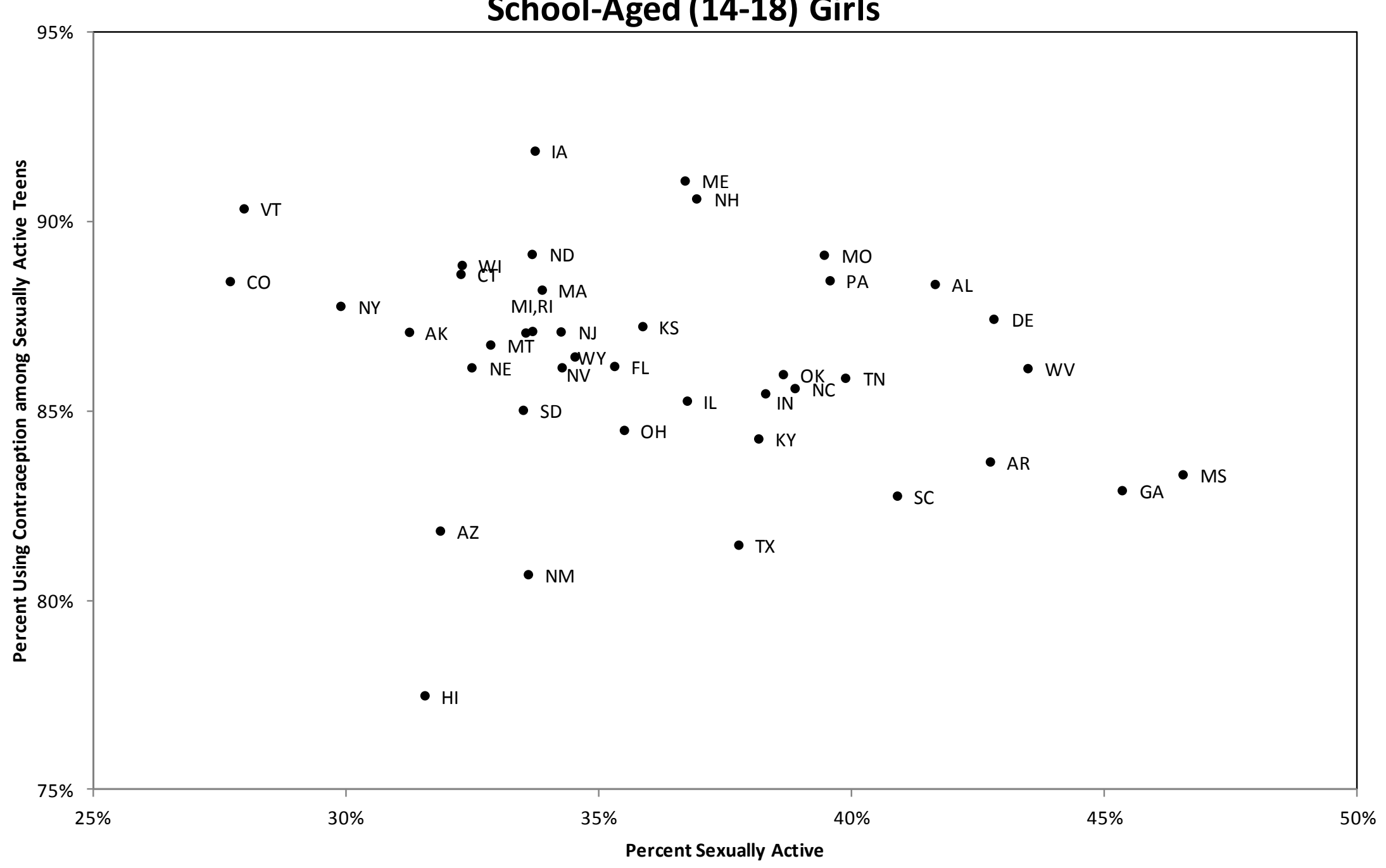

source: authors' calculations from the 2007 and 2009 YRBS state microdata. 
Figure 5: Rate of Nonmarital Childbearing by Age 20, by Mother's Level of Education and State Level of Income Inequality

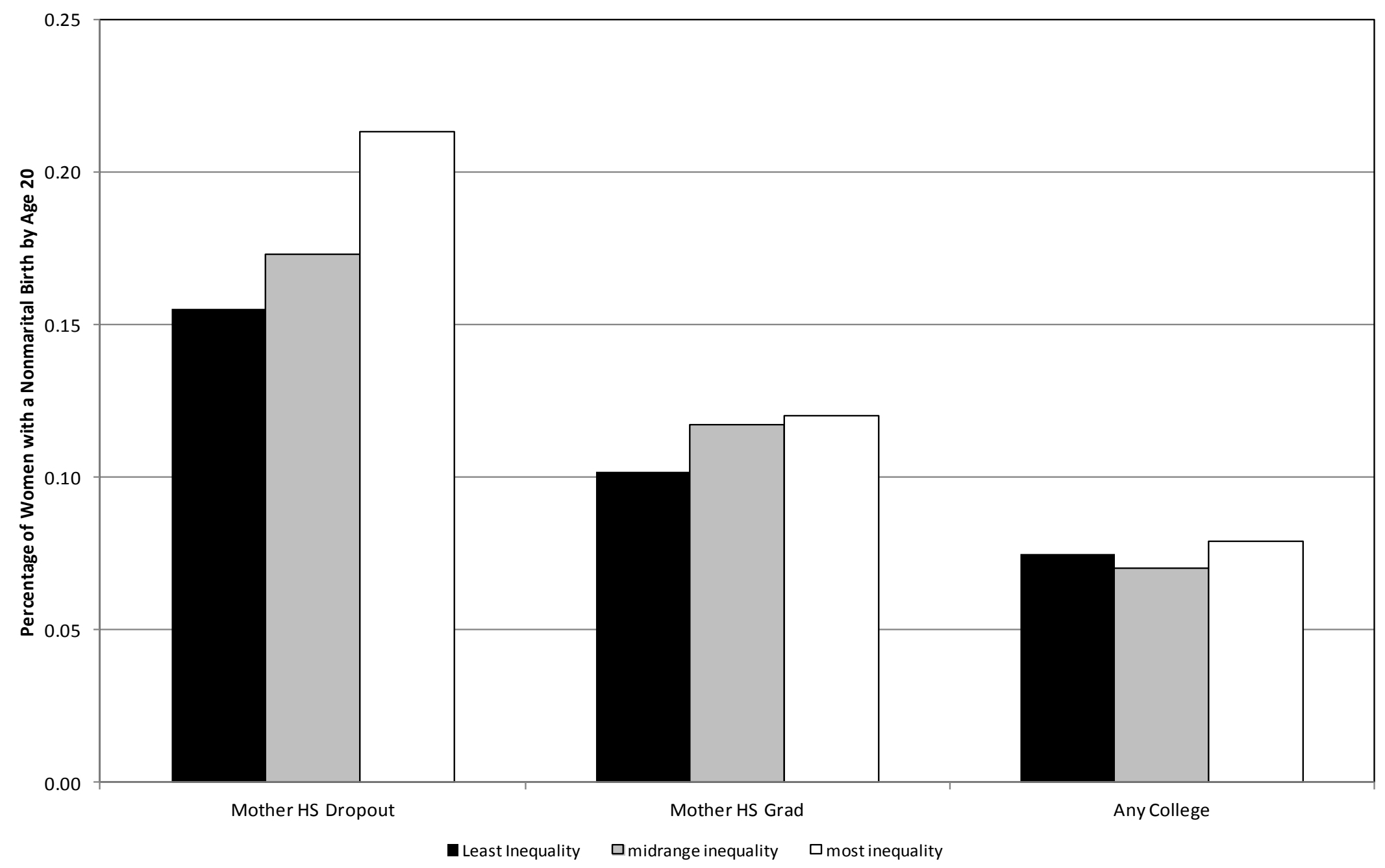

Source: Authors using data from the 1982, 1988, 1995, 2002, and 2006-2008 National Surveys of Family Growth. 